\title{
Towards Rational Prescription of Common Inhaler Medication in the Multimorbid COPD Patient
}

\author{
loanna Tsiligianni' \\ Kristian Jong Hoeines ${ }^{2}$ \\ Christian Jensen (D) $^{3}$ \\ Janwillem WH Kocks $\mathbb{D}^{4-6}$ \\ Björn Ställberg ${\left(D^{7}\right.}^{7}$ \\ Claudia Vicente ${ }^{8}$ \\ Rudi Peché (iD) ${ }^{9}$ \\ 'Department of Social Medicine, \\ University of Crete, Heraklion, Greece; \\ ${ }^{2}$ Tananger Legesenter DA, Sola, Norway; \\ ${ }^{3}$ Lægehuset Remisen, Præstø, Denmark; \\ ${ }^{4}$ General Practitioners Research Institute, \\ Groningen, the Netherlands; ${ }^{5}$ University \\ of Groningen, University Medical Center \\ Groningen, GRIAC Research Institute, \\ Groningen, the Netherlands; \\ ${ }^{6}$ Observational and Pragmatic Research \\ Institute, Singapore; ${ }^{7}$ Department of \\ Public Health and Caring Sciences, Family \\ Medicine and Preventive Medicine, \\ Uppsala University, Uppsala, Sweden; \\ ${ }^{8}$ Unidade Saúde Familiar Araceti, \\ Arazede, Portugal; ${ }^{9}$ Department of \\ Pneumology, ISPPC, CHU Charleroi, \\ Charleroi, Belgium
}

Correspondence: loanna Tsiligianni Department of Social Medicine, University of Crete, Voutes Campus, Heraklion, Crete, 71003, Greece Tel +302810394607

Email i.tsiligianni@uoc.gr

\begin{abstract}
COPD is a chronic disease, typically accompanied by multiple comorbid conditions. The need to apply several, and sometimes conflicting, disease-specific treatment guidelines, complicates the management of individual patients. Moreover, national and international recommendations evolve rapidly but provide limited guidance on the integrated approach in the multimorbid patient. Particularly bothersome is the fact that the presence of comorbidities may deteriorate the course of COPD, and inversely COPD may affect the outcome of the comorbid diseases. In addition, some effects of commonly prescribed COPD inhaler medications, including beta ${ }_{2}$-agonists, long-acting antimuscarinics and especially inhaled corticosteroids, mimic or worsen COPD-related comorbidities. Therefore, the authors combined their perspectives to formulate advice that may help physicians to improve COPD patient care in daily practice when comorbidities are present. Diabetes, atrial fibrillation, osteoporosis/fractures, infections (pneumonia and tuberculosis) and asthma were identified as areas where practicing clinicians should give special attention to the risk-benefit ratio of the inhaled medication. Overall, the presence of multimorbidity in a COPD patient should act as a signal to carefully reconsider the treatment choices.
\end{abstract}

Keywords: comorbidity, multimorbidity, polypharmacy, inhaler medication

\section{Introduction}

In the rapidly aging population with increasing longevity, responsibilities of physicians are shifting towards the management of chronic diseases. These chronic diseases often appear in clusters due to common risk factors (eg, COPD and lung cancer), shared pathobiological mechanisms (eg, accelerated ageing in COPD and hypertension) and side effects of COPD treatment (eg, development of diabetes). ${ }^{1,2}$ The majority of consultations nowadays involve patients with many coexisting chronic conditions, while particularly in primary care, the workload to apply practice guidelines increases steeply with increasing numbers of concomitant illnesses. ${ }^{3,4}$ Bringing treatment guidelines into practice is not easy because international and national recommendations may vary substantially, and local regulations are often misaligned with the rapidly evolving treatment recommendations. ${ }^{5}$ Healthcare delivery gets particularly complicated when entering the world of multimorbidity, where single disease-specific guidelines must be combined to treat individual patients. ${ }^{6}$ Rarely do these guidelines provide clear direction on multimorbidity, not even in patients with only two simultaneous diseases. ${ }^{7}$ 
In patients with COPD, multimorbidity and the associated risk of hospitalization and premature death are highly prevalent, including also a high level of polypharmacy and potential adverse drug reactions. ${ }^{1,5,8-12}$ For the treating physician, COPD is one out of the many chronic diseases to account for, while symptoms and signs are usually complex and attributable to several causes. ${ }^{13}$ Patients themselves, struggling with smoking addiction and shame about self-inflicted disease, rarely seek medical help for their respiratory problems outside acute situations. ${ }^{14}$ Also, due to the progressive course of COPD, patients become used to the symptoms, not valuing them as they should. An all-inclusive consultation approach with sufficient time devoted to COPD, is essential. ${ }^{15,16}$ Such a holistic approach should include theory-driven patient assessment models to facilitate smoking cessation, patient empowerment, programs for physical activity, physiotherapy, rehabilitation as well as raising adherence to treatment and limiting unnecessary pharmaceutical treatment.

This paper brings a fresh perspective on the management of the poly-medicated multimorbid COPD patient. Our objective is to assess and describe the impact of inhalation medication, including beta ${ }_{2}$-agonists (LABA), long-acting muscarinic antagonists (LAMA) and inhaled corticosteroids (ICS), as potential contributing factors to comorbid disease in COPD and formulate advice to enhance management of comorbid COPD patients.

\section{How Common is Multimorbidity in COPD and What are the Challenges?}

Most patients with COPD have a large number of long-term comorbidities, which affect their health outcomes and increase the risk of hospitalization and mortality. ${ }^{17}$ Importantly, COPD itself is also known to adversely influence the course of other conditions. ${ }^{13}$ The diagnosis of COPD tends to precede other comorbid conditions, at least in patients over 65 years of age. ${ }^{18}$ Concomitant diseases can also be overlooked because signs and symptoms overlap.

Up to $80 \%$ of patients with COPD suffer from at least one comorbid condition of clinical relevance; half of them have three or more. ${ }^{19}$ Comorbid conditions are even more frequent in women than men, and the prevalence increases with worsening COPD severity. ${ }^{19,20}$

Comorbidities often appear in clusters, which can be explained by common risk factors (eg, smoking, inactivity), shared underlying pathobiological mechanisms (eg, accelerated ageing), and the occurrence of side effects of COPD medication. . $^{1,21}$

Common comorbidities in patients with stable COPD include cardiovascular diseases (heart failure, ischemic heart disease, arrhythmias, peripheral vascular disease, hypertension), asthma, skeletal muscle dysfunction, osteoporosis, anxiety and depression, lung cancer, metabolic syndrome, diabetes, gastroesophageal reflux, bronchiectasis, and obstructive sleep apnea. ${ }^{13,21}$ Figure 1 (panel A) provides a graphical representation of the comorbidities found in large European studies. ${ }^{10,22-28}$ The analysis underlying this figure can be found in the Supplementary Data. The American Truven health database found that the most common comorbidities, ie, cardiovascular disease (35\%), diabetes (23\%), asthma (15\%), anemia (14\%), chronic kidney disease (10\%), depression $(10 \%)$, and osteoporosis (7\%), all highly contribute to morbidity and use of health care resources. ${ }^{29}$ The Swedish large, realworld, retrospective cohort, ARCTIC, which specifically examined patients from the primary care setting, showed significantly higher prevalence rates of lung cancer, heart failure, ischemic heart disease, hypertension, depression/ anxiety, sleep disorders, osteoporosis, stroke, osteoarthritis, and pulmonary embolism in the COPD population compared with the non-COPD population in primary care. ${ }^{25}$ Comorbidities also increased the occurrence of severe exacerbations in these COPD patients. Westerik et al calculated in their retrospective cohort study of more than fourteen thousand COPD patients from general practice in the Netherlands, that several comorbidities were significantly associated with an exacerbation frequency of $\geq 2$ exacerbations/year, ie, heart failure, blindness and low vision, pulmonary cancer, depression, prostate disorders, asthma, osteoporosis, diabetes, dyspepsia and peripheral vascular disease. ${ }^{26}$

\section{Evolving Treatment Guidelines}

While multimorbidity is omnipresent in daily clinical practice, the approach in clinical research is usually single disease-oriented, avoiding concomitant diseases via stringent study exclusion criteria or not reporting concomitant conditions. There is a clear need for more pragmatic studies that tackle complexity. ${ }^{13}$

GOLD has been a pioneer in this regard and, since a few years; has integrated the issue of multimorbidity in its reports, highlighting the importance of comorbidity 


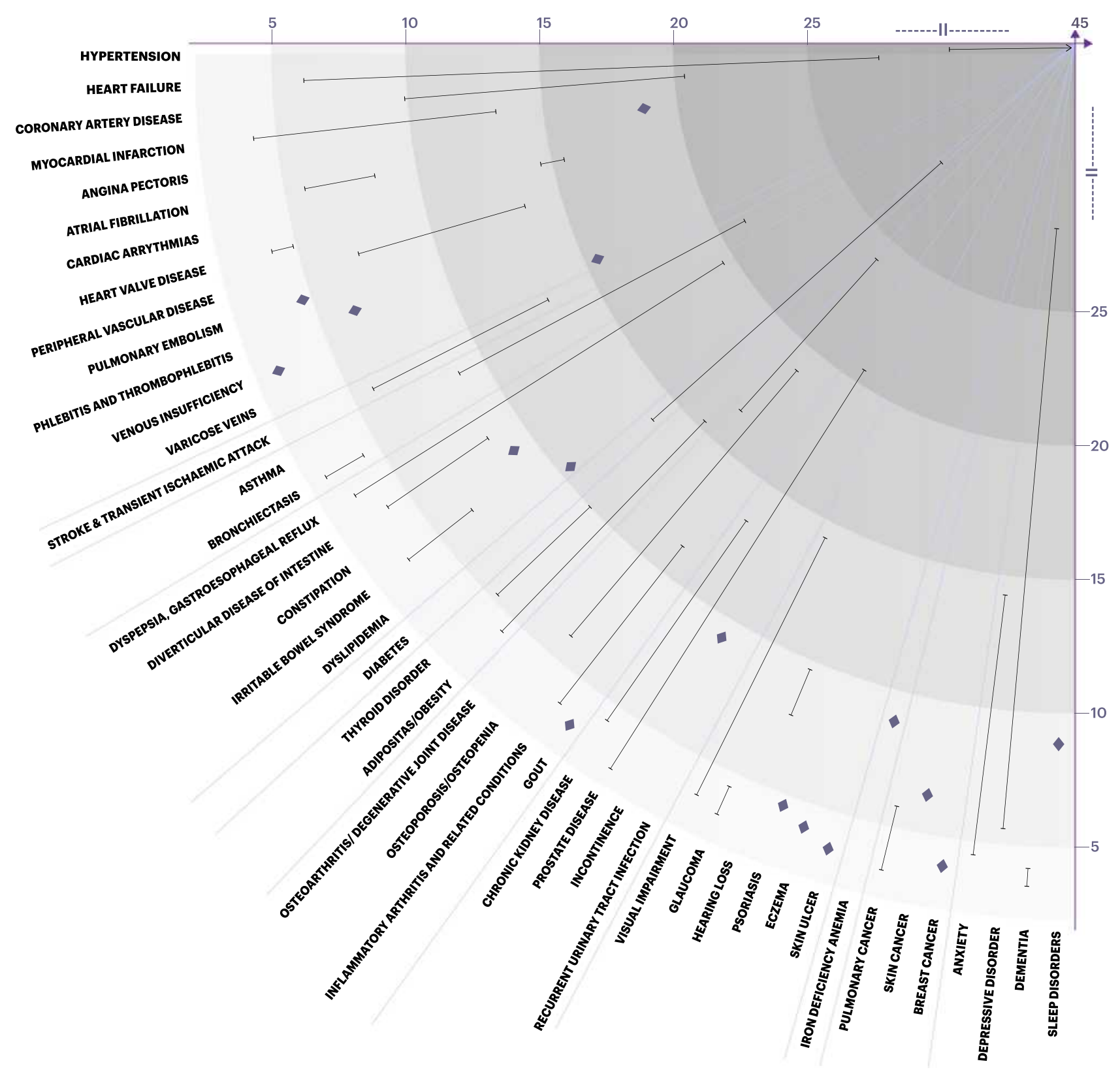

Figure I(A) Prevalence of frequent comorbid conditions (panel A)*. *Graphical representation of the comorbidities found in 6 large European studies (see Supplementary Data); lines (I-I) connect the minimal and maximal prevalence rates found in these studies; diamonds ( ) are used when the condition is reported in only one study.

assessment. ${ }^{13}$ Extrapolation into local practice guidelines remains scarce.

The current GOLD update (2021) has once more confirmed the central role of bronchodilation in the treatment of stable COPD. ${ }^{13}$ Inhaled bronchodilators are given on a regular basis to prevent or reduce symptoms, mainly breathlessness. The GOLD recommendations indicate that patients may be started on single or dual long-acting bronchodilator therapy. In patients with persistent dyspnea or exercise limitation on one bronchodilator, escalation to two bronchodilators is advised. In patients with persistent exacerbations despite dual bronchodilator treatment, blood eosinophil counts may identify patients with a greater likelihood of a beneficial response to adding ICS. ${ }^{13}$ Depending on the population and severity of COPD, this group of frequent exacerbators, with 2 or more exacerbations in the previous years, varies widely in the literature with estimates up to $38 \% .^{30-36}$ The SPIROMICS study collected data on a general COPD population and found that persistent exacerbators with two or more acute exacerbations 


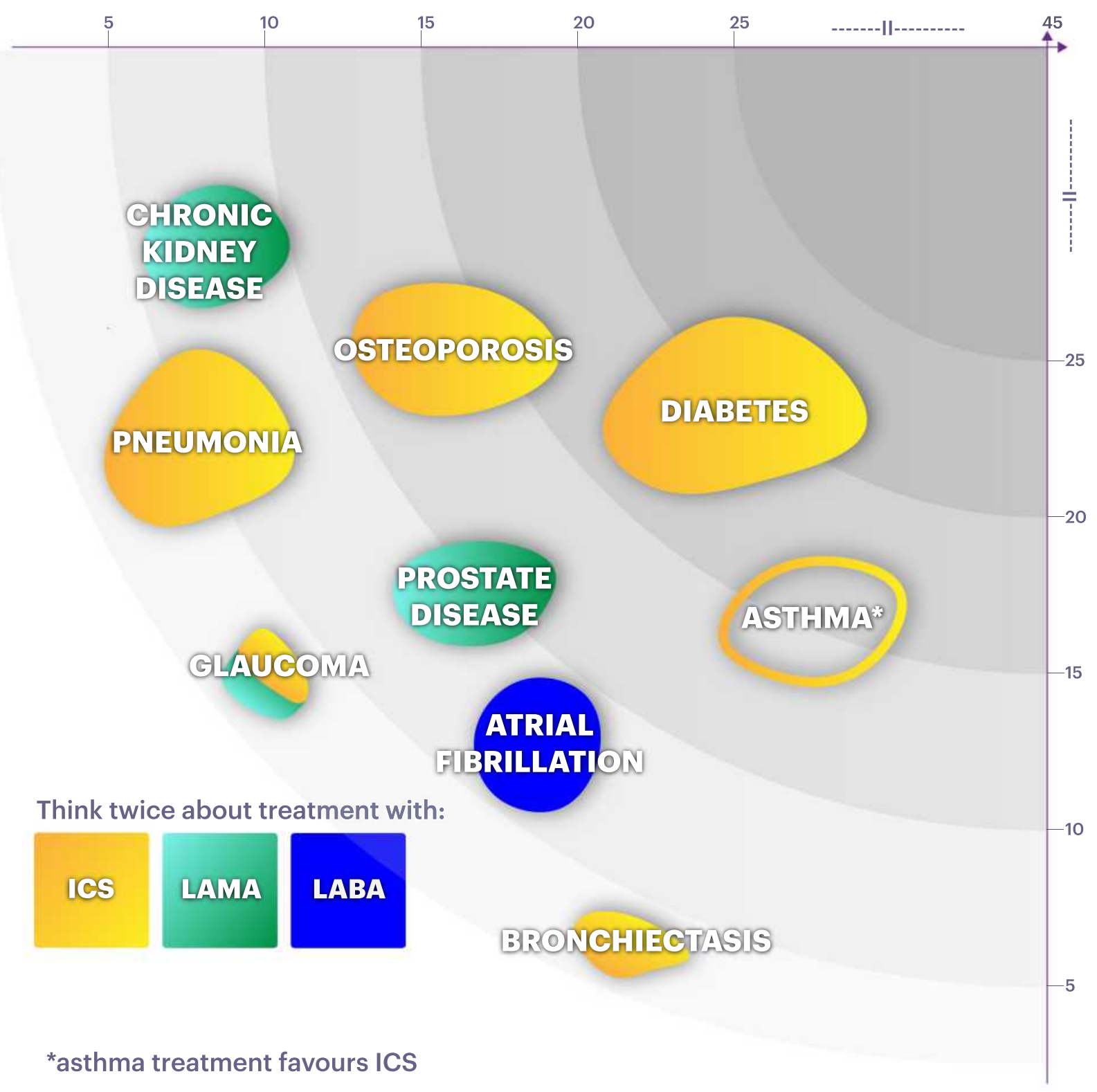

Figure I(B) Visual interpretation of COPD medication recommendations ${ }^{\S}$. ${ }^{\S}$ Pneumonia data based on Lipson ${ }^{28}$ and Papi. ${ }^{27}$

Abbreviations: COPD, chronic obstructive pulmonary disease; ICS, inhaled corticosteroid (yellow); LABA, long-acting $\beta_{2}$-agonist (blue); LAMA, long-acting antimuscarinic (green).

each year over a three-year period are rare $(2 \%) .{ }^{30}$ Since many studies have shown that the use of ICS increases the risk of pneumonia, the importance of the risk/benefit evaluation has been emphasized. ${ }^{28,37-39}$ Initial therapy with ICS in combination with a LABA may be the first choice only in selected patients, ie, patients with history of asthma, patients with a history of hospitalization(s) for exacerbations or $\geq 2$ moderate exacerbations per year, despite appropriate long-acting bronchodilator treatment, and patients with blood eosinophil counts $\geq 300$ cells $/ \mu \mathrm{L} .{ }^{13}$
Withdrawal of ICS must be considered if pneumonia, inappropriate original indication (eg, use of ICS to treat symptoms in the absence of a history of exacerbations) or lack of response to ICS occurs. ${ }^{13}$ Large studies have shown that gradual or abrupt withdrawal of ICS is feasible, and - according to Suissa's analysis of the Quebec Health Insurance Database - may result in a reduction of severe pneumonia. ${ }^{40-43}$ Initiatives for withdrawal of inhaled corticosteroids in primary care are represented in Table 1. 
Table I Initiatives for Withdrawal of Inhaled Corticosteroids in Primary Care

\begin{tabular}{|l|l|l|}
\hline Initiator & Tool & Description \\
\hline IPCRG & $\begin{array}{l}\text { Desktop } \\
\text { helper }^{74}\end{array}$ & $\begin{array}{l}\text { Easy tool developed by the IPCRG } \\
\text { to help physicians identifying } \\
\text { patients who would benefit from } \\
\text { ICS treatment vs those in whom it } \\
\text { may not be appropriate, and to } \\
\text { provide guidance on how to } \\
\text { withdraw ICS. Currently available } \\
\text { in English, Spanish and Portuguese. }\end{array}$ \\
\hline Sweden & $\begin{array}{l}\text { Roadmap for } \\
\text { ICS withdrawal }\end{array}$ & $\begin{array}{l}\text { A quick reference document } \\
\text { available in Swedish (http://www. } \\
\text { naaka.se/images/pdf/Nedtrappning- } \\
\text { ICS-vid-KOL-lathund.pdf) }\end{array}$ \\
\hline Netherlands & $\begin{array}{l}\text { ICS reduction } \\
\text { tool }\end{array}$ & $\begin{array}{l}\text { Based on the Dutch GP guidelines } \\
\text { and the IPCRG desktop helper, } \\
\text { adapted for the Dutch situation; } \\
\text { includes both identification of } \\
\text { overuse and suggestions for } \\
\text { monitoring after ICS deprescribing. }\end{array}$ \\
\hline Belgium & $\begin{array}{l}\text { ICS withdrawal } \\
\text { questionnaire }\end{array}$ & $\begin{array}{l}\text { Five questions for daily practice } \\
\text { developed by academic and non- } \\
\text { academic chest physicians to } \\
\text { provide guidance on (in) } \\
\text { appropriate use of ICS and to train } \\
\text { small focus groups of primary care } \\
\text { physicians. }\end{array}$ \\
\hline
\end{tabular}

Abbreviations: IPCRG, International Primary Care Respiratory Group; ICS, inhaled corticosteroids.

The COPD treatment recommendations have substantially evolved over the past decades before arriving at their current stage. The uptake of changing recommendations into international and local guidelines and to primary care routine is usually slow, and the COPD case has encountered particularly high resistance. ${ }^{44}$ Numerous examples illustrate the persistence of misalignment between guidance and current prescription patterns with over-prescription of LABA/ICS as a consequence. ${ }^{45}$ The Greek UNLOCK study showed that more than $50 \%$ of patients were treated with a LABA/ICS independently of the GOLD classification. GPs mentioned many reasons for this non-adherence to guidelines such as lack of updates of the local guidelines, restricted access to diagnostic procedures, and local prescription-reimbursement rules. ${ }^{44}$ A comparison of Swedish cohorts of COPD patients from both primary and secondary care found that maintenance treatment with LABA/ICS or ICS alone significantly decreased between 2005 and 2014, while a combination of
LABA/ICS plus LAMA had become the most commonly prescribed treatment in 2014. ${ }^{46}$

Furthermore, non-adherence to available guidelines may be partially explained by a range of limitations of the $\mathrm{ABCD}$ grading system, that seem to be not very widely used among specialists and primary care physicians (eg, ERS, ATS, ALAT, SEPAR guidelines). ${ }^{47-49}$ Since 2019 the ABCD grading system applies only for the initial COPD treatment. Follow-up treatment suggestions are based on the treatable traits, dyspnea, and exacerbations. ${ }^{13}$

\section{Inhaler Medication in the Multimorbid COPD Patient}

Thanks to long-term and extensive use of inhaled medications in the past decades, well-established tolerability profiles are available for each of the three major treatment categories, ie, LAMA, LABA and ICS (Table 2). Bronchodilators appear to be generally safe. Known adverse reactions of LAMA are dry mouth (most frequent, $15 \%$ of patients), constipation, headache, pharyngitis, urinary retention and acute glaucoma (if used with face mask). ${ }^{12,13,50}$ With LABA, consideration is given to systemic effects, including tremor, tachycardia, palpitations and changes in plasma potassium concentrations. ${ }^{12,13}$ Historically, LAMA and LABA use in COPD patients with cardiovascular disease has always been in special focus of safety monitoring. Today, extensive evidence has accumulated to support the safety of these drugs. ${ }^{51}$ It seems that higher risk for cardiovascular events is associated with the comorbidities chronic cardiovascular and/or chronic kidney disease, and history of frequent exacerbations, rather than associated with the use of inhaled bronchodilators. ${ }^{52}$ Consequently, current debate starts to focus on how the patient's cardiovascular condition may benefit from appropriate COPD treatment.

ICS are generally safe but should be used with caution in patients with COPD who have no history of asthma, considering the risk/benefit ratio, particularly when patients have many comorbidities. ${ }^{13}$ Long-term use of ICS has been associated with many local and systemic side effects (pneumonia, tuberculosis, mycobacteria, bone fracture, ophthalmologic effects, diabetes, candidiasis and dental decline). ${ }^{53,54}$ Some ICS-containing medications include a warning on glaucoma and cataract with longterm use of ICS, and patients are advised to consult an ophthalmologist if ocular symptoms occur. ${ }^{53,54}$

Managing multimorbid COPD patients is particularly challenging because of the large number of prescriptions and potential for adverse drug reactions. ${ }^{5,12}$ Patients with 
Table 2 Most Important Adverse Events Related to Inhaled COPD Maintenance Treatment

\begin{tabular}{|c|c|c|c|}
\hline \multirow{2}{*}{$\begin{array}{l}\text { Comorbid } \\
\text { Category }\end{array}$} & \multicolumn{3}{|l|}{ Medication } \\
\hline & $\operatorname{ICS}^{13,54}$ & LAMA $^{13}$ & $\operatorname{LABA}^{13,88}$ \\
\hline Cardiovascular & & & $\begin{array}{l}\text { Tachycardia } \\
\text { Rhythm disturbances (in susceptible patients) }\end{array}$ \\
\hline Respiratory & $\begin{array}{l}\text { Pneumonia } \\
\text { Mycobacterial infection (including } \\
\text { tuberculosis) }\end{array}$ & & \\
\hline Nervous system & & & Tremor \\
\hline Urinary tract & & Urinary symptoms & \\
\hline Metabolic & $\begin{array}{l}\text { Increased risk of diabetes } \\
\text { Poor control of diabetes } \\
\text { Decrease bone density/fractures }\end{array}$ & & $\begin{array}{l}\text { Hypokalemia (if combined with corticosteroids or } \\
\text { thiazide diuretics) }\end{array}$ \\
\hline Skin & Bruising & & \\
\hline Vision & $\begin{array}{l}\text { Glaucoma } \\
\text { Cataract }\end{array}$ & $\begin{array}{l}\text { Glaucoma (if used with face } \\
\text { mask) }\end{array}$ & \\
\hline Oropharyngeal & $\begin{array}{l}\text { Oral candidiasis } \\
\text { Hoarse voice } \\
\text { Dental decline }\end{array}$ & Dry mouth & \\
\hline
\end{tabular}

Abbreviations: COPD, chronic obstructive pulmonary disease; ICS, inhaled corticosteroid; LABA, long-acting $\beta_{2}$-agonist; LAMA, long-acting antimuscarinic.

COPD are often taking multiple (5 to 10 ) drugs simultaneously, while polypharmacy carries the risk that drugs with similar potential for adverse reactions are inadvertently combined. ${ }^{55}$ A cross-sectional UK Biobank study found that the risk for adverse effects of treatment combinations is particularly high in patients with COPD. Medications contributing to this risk (falls, renal injury, constipation, urinary retention, depression, bleeding) were largely indicated for the management of other associated morbidities rather than COPD ${ }^{56}$ Still, these findings should be carefully discussed due to the low response rate of the participants $(5 \%$ of the invited individuals participated in the study).

The situation becomes even more complex when comorbid conditions and adverse reactions to treatment look alike (Figure 1, panel B). The link between ICS use and reduced bone density, particularly in women with osteoporosis, the increased risk of diabetes, tuberculosis and pneumonia is a point of concern (Table 3 ).

\section{Comorbidities of Special Interest}

\section{Asthma}

While COPD and asthma are both inflammatory lung diseases, characterized by chronic airflow limitation, they are still two distinct diseases, that overlap. ${ }^{13}$ However, patients with asthma may have a higher risk for developing COPD.${ }^{57}$ It is currently estimated that both diseases co-exist in 10 to $20 \%$ of COPD patients. ${ }^{13,57,58}$ These patients with asthma-COPD overlap (ACO) have clinical features of both asthma and COPD, more intense eosinophilic bronchial inflammation, more severe respiratory symptoms and more frequent exacerbations. ${ }^{59}$ Recognizing the asthma component in COPD patients, which requires ICS prescription, is crucial..$^{60}$

\section{Osteoporosis/Fractures}

Osteoporosis is often underdiagnosed; women require particular consideration in this regard. ${ }^{61}$ Reduced bone density has been associated with ICS use, which increases the risk for fractures. ${ }^{62,63}$ In the meta-analysis of Loke et al, each $500 \mu \mathrm{g}$ increase in beclomethasone dose equivalent was paralleled with $9 \%$ increased risk of fractures. ${ }^{63}$ In the real life DACCORD cohort of 6611 COPD patients, exposure to ICS was associated with an increased risk of osteoporosis and should be taken into consideration. ${ }^{64}$ Moreover, repeated courses of systemic corticosteroids significantly increase the risk of osteoporosis and should be avoided if possible. ${ }^{13}$ 
Table 3 Relationship Between COPD Comorbidities and ICS Treatment

\begin{tabular}{|c|c|c|c|}
\hline \multirow{2}{*}{$\begin{array}{l}\text { Concomitant Condition } \\
\text { COPD }\end{array}$} & \multicolumn{2}{|c|}{ ICS Treatment } & \multirow{2}{*}{$\begin{array}{l}\text { Ref } \\
{[13]}\end{array}$} \\
\hline & $\mathbf{S}$ & $\begin{array}{l}\text { If response to bronchodilator treatment is insufficient, adding ICS may be considered if blood } \\
\text { eosinophil counts } \geq 300 \text { cells } / \mu \mathrm{L} \text { or } \geq 100 \text { cells/ } \mu \mathrm{L} \text { in COPD patients with } \geq 2 \text { moderate } \\
\text { exacerbations* or } \geq 1 \text { exacerbation requiring hospitalization. Initiation therapy with LABA/ICS } \\
\text { may be the first choice in selected COPD patients (symptomatic with frequent exacerbations and } \\
\text { blood eosinophil counts } \geq 300 \text { cells/ } / \mathrm{L} \text { ). } \\
\text { A follow-up treatment in combination with LAMA and/or LABA, in selected patients }\end{array}$ & \\
\hline Asthma & $\mathbf{R}$ & $\begin{array}{l}\text { LABA/ICS may be first choice in COPD patients with a history of asthma and asthma-COPD } \\
\text { overlap }\end{array}$ & [13] \\
\hline Pneumonia & C & $\begin{array}{l}\text { Regular treatment with ICS increases the risk of pneumonia, particularly in patients with severe } \\
\text { COPD. De-escalation of ICS must be considered. }\end{array}$ & [13] \\
\hline Osteoporosis/fractures & C & ICS have been associated with increased bone loss and fracture risk. Consideration in women. & [6I-63] \\
\hline Diabetes and pre-diabetes & C & ICS, particularly high doses, have been associated with onset and progression of diabetes. & {$[65,66]$} \\
\hline Bronchiectasis & C & $\begin{array}{l}\text { ICS may not be indicated in patients with bacterial colonization or recurrent lower respiratory } \\
\text { tract infections. }\end{array}$ & {$[13,84]$} \\
\hline $\begin{array}{l}\text { Mycobacterial infection } \\
\text { (including tuberculosis) }\end{array}$ & C & ICS, particularly high doses, were shown to increase the risk of tuberculosis. & [7I] \\
\hline
\end{tabular}

Notes: *Moderate exacerbation: defined as exacerbation treated with short-acting bronchodilators plus antibiotics and/or oral corticosteroids. ${ }^{13}$

R , Recommended (green); S , Selected patients (yellow); C , Caution (red).

Abbreviations: COPD, chronic obstructive pulmonary disease; ICS, inhaled corticosteroid; LABA, long-acting $\beta_{2}$-agonist; LAMA, long-acting antimuscarinic.

\section{Diabetes}

Diabetes occurs frequently in COPD but the prevalence varies across epidemiological studies. ${ }^{5}$ Administration of ICS has been reported to augment new onset of diabetes as well as progression. ${ }^{65,66}$ According to the historical matched cohort study of Price et al, prescribing ICS to COPD patients with type 2 diabetes had a negative impact on diabetes control: increase in HbA1C levels, more diabetes-related general practice visits, and more prescription of glucose strip compared with matched patients not prescribed ICS. ${ }^{66}$ Higher cumulative doses of ICS were associated with higher risk of diabetes progression. Importantly, the authors pointed to the fact that some effects were stronger in mild-to-moderate COPD patients, who should not have received ICS according to the treatment guidelines. Similarly, the analysis of patients with respiratory disease of the Quebec health insurance database showed that current use of ICS was associated with $34 \%$ increase in onset of diabetes in patients initially free of diabetes and $34 \%$ increase in the rate of diabetes progression to use of insulin among users of oral hypoglycemic agents. ${ }^{65}$ The risk increased with higher doses of ICS.
Based on the Australian retrospective study of administrative claims data, Caughey et al recommended constant revision of corticosteroid dose (inhaled and systemic) in patients with diabetes and COPD, to ensure that the lowest effective doses are used. ${ }^{67}$ Admission to hospital for diabetes complications was $94 \%$ more likely in patients who received $\geq 0.83$ DDD (total defined daily dose) than in those who were not treated with corticosteroid.

\section{Pneumonia and Tuberculosis}

The Swedish ARTIC study demonstrated that patients with COPD have a more than four-fold greater risk of pneumonia compared with the matched non-COPD reference group. ${ }^{68}$ In patients with mild to moderate COPD (FEV $\geq 50 \%$ ) using ICS, the risk of pneumonia increased by $20-30 \%$ compared with patients not using ICS. ${ }^{68}$ Aligned with this finding, GOLD 2021 and ERS 2020 recommend to withdraw ICS amongst other reasons (eg, patients without frequent exacerbations, history of frequent exacerbations and $<300$ eosinophils cells $/ \mu \mathrm{L}$ ), also if adverse events, such as pneumonia occur. ${ }^{13,69}$ Moreover, the metaanalysis performed by Pavord et al reported that patients with a low baseline blood eosinophil count $(<150-200$ cells/ $\mu \mathrm{L})$ are at increased risk of pneumonia. ${ }^{70}$ This finding is 
also reflected in the GOLD 2020 recommendations, considering a strong support for ICS if history of hospitalizations for exacerbations of COPD, $\geq 2$ exacerbations per year (despite long acting bronchodilation), history of concomitant asthma, and a consideration of use if blood eosinophil counts $100-300$ cells $/ \mu \mathrm{L}$, one moderate exacerbation of COPD per year (despite long acting bronchodilation). Most importantly, GOLD suggests no use/withdrawal in repeated pneumonia events, blood eosinophils $<100$ cells/ $\mu \mathrm{L}$, history of mycobacterial infection. ${ }^{13}$

Suissa et al calculated, using the Quebec health insurance databases, that discontinuation of ICS was associated with a $37 \%$ decrease in the rate of serious pneumonia. ${ }^{42}$ The risk reduction was already evident in the first month ( $20 \%$ reduction) and further decreased to $50 \%$ by the fourth month of withdrawal.

Another analysis of the Quebec health insurance database found that the use of ICS was also associated with an increase of tuberculosis development. ${ }^{71}$ The association was dose-dependent.

\section{Atrial Fibrillation}

Atrial fibrillation may occur as a comorbidity in patients with worsening COPD. ${ }^{13}$ In the past, concerns have been raised about the potential arrhythmogenic risk of bronchodilators. In the meantime, this has been the object of research in clinical trials, including patients at risk, which showed that the risk was acceptable. ${ }^{13,72,73}$ According to GOLD 2021, available evidence suggests an overall acceptable safety profile for LABA, LAMA (and ICS). Nevertheless, caution is advised when using short-acting beta $_{2}$-agonists and theophylline, which may precipitate atrial fibrillation and make control of the ventricular response rate difficult. ${ }^{13}$ Still, further research, such as post-marketing surveillance or real-world studies, is required to sufficiently assess this topic and avoid challenges related to sample representativeness and external validity. The GOLD guidelines do not recommend altered treatment in the presence of atrial fibrillation, ${ }^{13}$ but caution may be advisable in susceptible patients. ${ }^{74}$ Evidence also confirms that $\beta_{2}$-agonists and selective $\beta_{1}$-antagonists can be used concomitantly in the management of coexisting COPD and heart failure. ${ }^{13}$

\section{Other Diseases and Interactions}

Glaucoma has been reported when LAMA is used with face mask. ${ }^{13}$ The use of ICS has been associated with visual impairment (eg, cataract, glaucoma). ${ }^{75}$
Urinary symptoms have been reported in patients taking LAMA, but the causal relationship has not been established. ${ }^{13,76}$ Men with lower urinary tract symptoms (LUTS) or benign prostatic hyperplasia (BPH) may develop acute urinary retention when treated with LAMA. $^{77}$ In patients with moderate to severe renal impairment, LAMA should only be used if the expected benefits outweigh the potential risk. Special attention is required with anticoagulant treatment in patients susceptible to easy bruising (adverse effect of ICS). ${ }^{54}$ Also, concomitant use of common drugs that are CYP3A4 inhibitors (eg, ketoconazole, clarithromycin, verapamil and ingestion of grapefruit) may increase the bioavailability and risk of ICS. $^{78}$ The occasional use of systemic corticosteroids should also require consideration as it increases the steroid burden and may increase the risk of ICSrelated adverse effects. ${ }^{54}$

\section{Phenotypes and Treatable Traits}

In addition to focus on COPD patients' co-morbid conditions, other patient characteristics, so-called phenotypes may be relevant, especially in multimorbid COPD patients. There is increasing interest in phenotyping of COPD patients to guide clinical practice to the needs of the individual patient. ${ }^{79}$

Common clinical phenotypes include patients with low exacerbation risk, frequent exacerbators with emphysema, frequent exacerbators with chronic bronchitis and patients with asthma-COPD overlap. ${ }^{80}$ Bronchodilators are the preferred treatment option in non-frequent exacerbators, except for patients with asthma-COPD overlap, who should always be treated with ICS in addition to bronchodilators. In persistent exacerbators, the role of blood eosinophils as biomarker has gained importance, since there are alternatives to ICS, such as roflumilast in some countries (appropriate in patients with chronic bronchitis) and azithromycin (appropriate in selected patients with frequent infections and/or bronchiectasis and initiated by a pulmonologist). ${ }^{13,80}$ In the treatment algorithm for follow-up, GOLD 2021 differentiates patients according to the treatable trait, dyspnea or exacerbations. ${ }^{13}$

From this perspective, some interesting findings, to take into consideration, are listed below: (1) Eosinophilic airway inflammation can be considered a treatable trait identified via high eosinophil counts. ${ }^{70}$ (2) Patients with emphysema may have a higher risk of lung cancer, osteoporosis and loss of muscle mass. ${ }^{72,81}$ (3) Cigarette smoking is a major risk for COPD and 
cardiovascular disease, osteoporosis, and lung cancer. ${ }^{21}$ Reduced responsiveness to the anti-inflammatory effects of steroids, make ICS less helpful in smoking COPD patients. $^{82}$ (4) Over $50 \%$ of COPD patients have an altered airway microbiome, and the frequency of exacerbations was found higher in patients with colonization of the lower airways. ${ }^{83}$ Long-term ICS treatment affected the bacterial load, particularly in patients with low eosinophil counts. $^{84}$ (5) Older patients and patients with low body mass index are at increased risk for pneumonia and loss of muscle mass. (6) Physicians should also consider that bronchiectasis and interstitial lung diseases may occur in these patients.

\section{How to Manage in Routine Clinical Practice}

While the GOLD recommendations raise "reduce risk (prevent and treat exacerbations)" as a primary goal of COPD treatment, our panel suggested to expand this goal to "reducing the risk of exacerbations and the risk of adverse health events that may affect the patient in the future".

The management of multimorbid COPD patients is per definition - personalized medicine. Physicians should adopt systematic ways to follow COPD patients. Herein, multimorbidity should be taken as a call to action to reconsider COPD treatment. This is due to the fact that, multimorbid patients who comprise the vast majority of the COPD population are at greater risk of adverse outcomes and treatment complications, they are more likely to receive ineffective care or have lower adherence to treatment, ${ }^{85}$ have higher health care costs, and worse survival. Therefore, this group of COPD patients requires a personalized treatment plan that takes into account individual ability to cope with day-to-day activities, adhere to medication, additional needs for healthcare services and multiple regular medicines, long-term physical and mental health conditions, frailty or falls and unplanned emergency hospitalizations. ${ }^{16}$

Also, the interface between symptoms of comorbid diseases and side effects of medication should be considered. Especially if comorbidities as diabetes, atrial fibrillation, osteoporosis/fractures, infections (pneumonia and tuberculosis) or asthma are present, it is important to carefully consider the individual risk/benefit balance when prescribing medication, ie, discontinuation of ICS treatment in patients without an appropriate indication for ICS, while prescribing ICS-containing treatment in patients who need it according to the treatment guidelines. One should not forget simple preventative measures, such as vitamin D - calcium supplementation in case of osteoporosis risk.

Initiatives to integrate COPD into the holistic consultation may be an interesting incentive in primary care. Nurses and patient associations may also help in getting the messages to the patients, because patients often do not discuss their symptoms of COPD. Good coordination of first, and second-line patient management is required. The approach depends on the availability of local resources but should always properly consider patient benefits.

In summary, to improve the management of comorbid COPD patients, the following points should be considered:

Pay attention to co-morbid conditions; monitor and consider how COPD medications may potentially influence the comorbid diseases.

In the primary care setting, assess at least annually patient treatments and adjust medications as appropriate. This will allow re-adjustment of the individualized care plan, check inhalation technique and adherence to treatment, avoid unnecessary medication (especially ICS overuse or misuse in the context of comorbidity) and reveal new needs of the patient, enhance quality of life and minimize treatment burden and healthcare costs.

Integrate assessment of comorbidities and drug interactions in medical practice software to trigger alerts (eg, monitoring for diabetes if ICS is prescribed).

Empower multimorbid COPD patients to cope with disease- and medication-related information. Short advice and patient/caregiver counselling sessions about selfmanagement may respond to their physical and mental needs and help to reduce anxiety and risk for depression.

Consider price and adherence to medication, including stopping of inappropriate medication.

Carefully evaluate the indication before initiating ICS treatment.

\section{Conclusions}

Since comorbidities are frequent in COPD patients, there is an urgent need for specific recommendations to guide physicians in their multimorbid approach. The current work reflects on the benefit/risk of current inhaled medications in a point-by-point and graphical way, in order to help physicians, who manage these multimorbid and polymedicated patients in daily practice. 


\section{Acknowledgments}

Medical writing assistance was supported financially by Boehringer Ingelheim and provided by Hedwig Stals of HD Consultancy, under the authors' conceptual direction and based on feedback from the authors. The figures were created by Jack de Haas, Boehringer Ingelheim. Boehringer Ingelheim has given logistical support to organize the teleconferences and the meeting of the authors to discuss this concept.

\section{Author Contributions}

All authors made a significant contribution to the work reported, in the conception, study design, execution, acquisition of data, analysis and interpretation; they took part in drafting, revising and critically reviewing the article; gave final approval of the version to be published; have agreed on the journal to which the article has been submitted; and agree to be accountable for all aspects of the work.

\section{Disclosure}

IT received honoraria for talks and advisory boards of Novartis, GSK, Boehringer Ingelheim, grants from Elpen, GSK Greece, Astra Zeneca Greece, outside the submitted work.

$\mathrm{KH}$ has received honoraria for educational activities and lectures from AstraZeneca, Boehringer Ingelheim, GSK, Novartis, Novo Nordisk, and Sanofi, and has served on advisory boards arranged by AstraZeneca, Novartis, GSK, Sanofi, Boehringer Ingelheim, Teva and Chiesi.

$\mathrm{CJ}$ received honoraria for talks and participating in advisory boards for Astellas Pharma, AstraZeneca, Boehringer Ingelheim, Novo Nordisk; all outside the submitted work.

JWK reports grants and personal fees from AstraZeneca, grants, and personal fees from Boehringer Ingelheim, grants from Chiesi, grants and personal fees from GSK, grants and personal fees from Novartis, grants from Mundi Pharma, grants from TEVA, outside the submitted work.

BS has received honoraria for educational activities and lectures from AstraZeneca, Boehringer Ingelheim, GlaxoSmithKline, Novartis, Meda and Teva and has served on advisory boards arranged by AstraZeneca, Novartis, GSK, Boehringer Ingelheim, Teva and Meda and Chiesi.

$\mathrm{CV}$ has received honoraria for educational activities and/or talks and/or advisory boards from AstraZeneca, Boehringer Ingelheim, GSK, and personal fees from Mylan, all outside the submitted work.
RP received honoraria for talks and/or advisory boards of Chiesi, AstraZeneca, Novartis, Boehringer Ingelheim, GSK, Sanofi; all outside the submitted work. Boehringer Ingelheim was not involved in directing the content of the manuscript and was only given the opportunity to review the manuscript for factual accuracy.

All recommendations stated in the manuscript are thus reflective of the authors' opinions, and as such are not necessarily supported by Boehringer Ingelheim. The treatment management recommendations supported by Boehringer Ingelheim are specified in the Summary of Product Characteristics.

\section{References}

1. Divo MJ, Casanova C, Marin JM, et al. COPD comorbidities network. Eur Respir J. 2015;46(3):640. doi:10.1183/09031936.0 0171614

2. Barnes PJ. Senescence in COPD and its comorbidities. Annu Rev Physiol. 2017;79:517-539. doi:10.1146/annurev-physiol-022516034314

3. Salisbury C, Johnson L, Purdy S, Valderas JM, Montgomery AA. Epidemiology and impact of multimorbidity in primary care: a retrospective cohort study. Br J Gen Pract. 2011;61(582):e12-21. doi:10.3399/bjgp11X548929

4. Buffel Du Vaure C, Ravaud P, Baron G, Barnes C, Gilberg S, Boutron I. Potential workload in applying clinical practice guidelines for patients with chronic conditions and multimorbidity: a systematic analysis. BMJ Open. 2016;6(3):e010119. doi:10.1136/bmjopen-2015010119

5. Tsiligianni IG, Kosmas E, Van der Molen T, Tzanakis N. Managing comorbidity in COPD: a difficult task. Curr Drug Targets. 2013;14 (2):158-176. doi:10.2174/1389450111314020004

6. Dorenkamp S, Mesters I, Teijink J, de Bie R. Difficulties of using single-diseased guidelines to treat patients with multiple diseases. Front Public Health. 2015;3:67. doi:10.3389/fpubh.2015.00067

7. Hillas G, Perlikos F, Tsiligianni I, Tzanakis N. Managing comorbidities in COPD. Int J Chron Obstruct Pulmon Dis. 2015;10:95-109. doi:10.2147/COPD.S54473

8. Lozano R, Naghavi M, Foreman K, et al. Global and regional mortality from 235 causes of death for 20 age groups in 1990 and 2010: a systematic analysis for the Global Burden of Disease Study 2010. Lancet (London, England). 2012;380(9859):2095-2128. doi:10.1016/ S0140-6736(12)61728-0

9. Quaderi SA, Hurst JR. The unmet global burden of COPD. Glob Health Epidemiol Genom. 2018;3:e4. doi:10.1017/gheg.2018.1

10. Chetty U, McLean G, Morrison D, Agur K, Guthrie B, Mercer SW. Chronic obstructive pulmonary disease and comorbidities: a large cross-sectional study in primary care. Br J Gen Pract. 2017;67 (658):e321-e328. doi:10.3399/bjgp17X690605

11. Mounce LTA, Campbell JL, Henley WE, Tejerina Arreal MC, Porter I, Valderas JM. Predicting incident multimorbidity. Ann Fam Med. 2018;16(4):322-329. doi:10.1370/afm.2271

12. Morrison D, Agur K, Mercer S, Eiras A, Gonzalez-Montalvo JI, Gruffydd-Jones K. Managing multimorbidity in primary care in patients with chronic respiratory conditions. NPJ Prim Care Respir Med. 2016;26:16043. doi:10.1038/npjpcrm.2016.43

13. Global Initiative for Chronic Obstructive Lung Disease (GOLD). 2021 global strategy for prevention, diagnosis and management of COPD; 2021. Available from: https://goldcopd.org/gold-reports/. Accessed April 10, 2021. 
14. Sheridan N, Kenealy T, Salmon E, Rea H, Raphael D, SchmidtBusby J. Helplessness, self blame and faith may impact on self management in COPD: a qualitative study. Prim Care Respir J. 2011;20(3):307-314. doi:10.4104/pcrj.2011.00035

15. Sandelowsky H, Hylander I, Krakau I, Modin S, Stallberg B, Nager A. Time pressured deprioritization of COPD in primary care: a qualitative study. Scand J Prim Health Care. 2016;34(1):55-65. doi:10.3109/02813432.2015.1132892

16. Vanfleteren LE, Spruit MA, Franssen FM. Tailoring the approach to multimorbidity in adults with respiratory disease: the NICE guideline. Eur Respir J. 2017;49(2):1601696. doi:10.1183/ 13993003.01696-2016

17. Smith MC, Wrobel JP. Epidemiology and clinical impact of major comorbidities in patients with COPD. Int $J$ Chron Obstruct Pulmon Dis. 2014;9:871-888. doi:10.2147/COPD.S49621

18. Tényi Á, Vela E, Cano I, et al. Risk and temporal order of disease diagnosis of comorbidities in patients with COPD: a population health perspective. BMJ Open Respir Res. 2018;5(1):e000302. doi:10.1136/bmjresp-2018-000302

19. Dal Negro RW, Bonadiman L, Turco P. Prevalence of different comorbidities in COPD patients by gender and GOLD stage. Multidiscip Respir Med. 2015;10(1):24. doi:10.1186/s40248-015-0023-2

20. Barr RG, Celli BR, Mannino DM, et al. Comorbidities, patient knowledge, and disease management in a national sample of patients with COPD. Am J Med. 2009;122(4):348-355. doi:10.1016/j. amjmed.2008.09.042

21. Decramer M, Janssens W, Miravitlles M. Chronic obstructive pulmonary disease. Lancet. 2012;379(9823):1341-1351. doi:10.1016/ S0140-6736(11)60968-9

22. Cazzola M, Bettoncelli G, Sessa E, Cricelli C, Biscione G. Prevalence of comorbidities in patients with chronic obstructive pulmonary disease. Respir Int Rev Thorac Dis. 2010;80(2):112-119. doi: $10.1159 / 000281880$

23. Greulich T, Weist BJD, Koczulla AR, et al. Prevalence of comorbidities in COPD patients by disease severity in a German population. Respir Med. 2017;132:132-138. doi:10.1016/j.rmed.2017.10.007

24. Divo MJ, Celli BR, Poblador-Plou B, et al. Chronic Obstructive Pulmonary Disease (COPD) as a disease of early aging: evidence from the EpiChron Cohort. PLoS One. 2018;13(2):e0193143. doi:10.1371/journal.pone. 0193143

25. Ställberg B, Janson C, Larsson K, et al. Real-world retrospective cohort study ARCTIC shows burden of comorbidities in Swedish COPD versus non-COPD patients. NPJ Prim Care Respir Med. 2018;28(1):33. doi:10.1038/s41533-018-0101-y

26. Westerik JA, Metting EI, van Boven JF, Tiersma W, Kocks JW, Schermer TR. Associations between chronic comorbidity and exacerbation risk in primary care patients with COPD. Respir Res. 2017;18 (1):31. doi:10.1186/s12931-017-0512-2

27. Papi A, Vestbo J, Fabbri L, et al. Extrafine inhaled triple therapy versus dual bronchodilator therapy in chronic obstructive pulmonary disease (TRIBUTE): a double-blind, parallel group, randomised controlled trial. Lancet (London, England). 2018;391 (10125):1076-1084. doi:10.1016/S0140-6736(18)30206-X

28. Lipson DA, Barnhart F, Brealey N, et al. Once-daily single-inhaler triple versus dual therapy in patients with COPD. $N$ Engl $J$ Med 2018;378:1671-1680. doi:10.1056/NEJMoa1713901

29. Mannino DM, Higuchi K, Yu TC, et al. Economic burden of COPD in the presence of comorbidities. Chest. 2015;148(1):138-150. doi:10.1378/chest.14-2434

30. Han MK, Quibrera PM, Carretta EE, et al. Frequency of exacerbations in patients with chronic obstructive pulmonary disease: an analysis of the SPIROMICS cohort. Lancet Respir Med. 2017;5 (8):619-626. doi:10.1016/S2213-2600(17)30207-2

31. Hurst JR, Vestbo J, Anzueto A, et al. Susceptibility to exacerbation in chronic obstructive pulmonary disease. N Engl J Med. 2010;363 (12):1128-1138. doi:10.1056/NEJMoa0909883
32. Kardos P, Vogelmeier C, Worth H, et al. A two-year evaluation of the 'real life' impact of COPD on patients in Germany: the DACCORD observational study. Respir Med. 2017;124:57-64. doi:10.1016/j. rmed.2017.02.007

33. Lange P, Marott JL, Vestbo J, et al. Prediction of the clinical course of chronic obstructive pulmonary disease, using the new GOLD classification: a study of the general population. Am J Respir Crit Care Med. 2012;186(10):975-981. doi:10.1164/rccm.201207$12990 \mathrm{C}$

34. Vogelmeier CF, Kostikas K, Fang J, et al. Evaluation of exacerbations and blood eosinophils in UK and US COPD populations. Respir Res. 2019;20(1):178. doi:10.1186/s12931-019-1130-y

35. Koblizek V, Milenkovic B, Barczyk A, et al. Phenotypes of COPD patients with a smoking history in Central and Eastern Europe: the POPE Study. Eur Respir J. 2017;49(5):1601446. doi:10.1183/ 13993003.01446-2016

36. Miravitlles M, Barrecheguren M, Román-Rodríguez M. Frequency and characteristics of different clinical phenotypes of chronic obstructive pulmonary disease. Int J Tuberc Llung Dis. 2015;19 (8):992-998. doi:10.5588/ijtld.15.0021

37. Wedzicha JA, Calverley PM, Seemungal TA, et al. The prevention of chronic obstructive pulmonary disease exacerbations by salmeterol/ fluticasone propionate or tiotropium bromide. Am J Respir Crit Care Med. 2008;177(1):19-26. doi:10.1164/rccm.200707-973OC

38. Wedzicha JA, Banerji D, Chapman KR, et al. Indacaterolglycopyrronium versus salmeterol-fluticasone for COPD. $N$ Engl $J$ Med. 2016;374(23):2222-2234. doi:10.1056/NEJMoa1516385

39. Calverley PM, Anderson JA, Celli B, et al. Salmeterol and fluticasone propionate and survival in chronic obstructive pulmonary disease. $N$ Engl J Med. 2007;356(8):775-789. doi:10.1056/ NEJMoa063070

40. Magnussen H, Disse B, Rodriguez-Roisin R, et al. Withdrawal of inhaled glucocorticoids and exacerbations of COPD. $N$ Engl J Med. 2014;371(14):1285-1294. doi:10.1056/NEJMoa1407154

41. Chapman KR, Hurst JR, Frent SM, et al. Long-term triple therapy de-escalation to indacaterol/glycopyrronium in patients with Chronic Obstructive Pulmonary Disease (SUNSET): a randomized, double-blind, triple-dummy clinical trial. Am J Respir Crit Care Med. 2018;198(3):329-339. doi:10.1164/rccm.201803-0405OC

42. Suissa S, Coulombe J, Ernst P. Discontinuation of inhaled corticosteroids in COPD and the risk reduction of Pneumonia. Chest. 2015;148(5):1177-1183. doi:10.1378/chest.15-0627

43. Rossi A, van der Molen T, Del Olmo R, et al. INSTEAD: a randomised switch trial of indacaterol versus salmeterol/fluticasone in moderate COPD. Eur Respir J. 2014;44(6):1548-1556. doi:10.1183/09031936.00126814

44. Tsiligianni I, Kampouraki M, Ierodiakonou D, Poulonirakis I, Papadokostakis P. COPD patients' characteristics, usual care, and adherence to guidelines: the Greek UNLOCK study. Int $J$ Chron Obstruct Pulmon Dis. 2019;14:547-556. doi:10.2147/COPD.S185362

45. Drivenes E, Ostrem A, Melbye H. Predictors of ICS/LABA prescribing in COPD patients: a study from general practice. BMC Fam Pract. 2014;15:42. doi:10.1186/1471-2296-15-42

46. Sundh J, Aberg J, Hasselgren M, et al. Factors influencing pharmacological treatment in COPD: a comparison of 2005 and 2014. Eur Clin Respir J. 2017;4(1):1409060. doi:10.1080/20018525.20 17.1409060

47. Nici L, Mammen MJ, Charbek E, et al. Pharmacologic management of chronic obstructive pulmonary disease. An Official American Thoracic Society clinical practice guideline. Am J Respir Crit Care Med. 2020;201(9):e56-e69. doi:10.1164/rccm.202003-0625ST

48. Wedzicha JA, Calverley PMA, Albert RK, et al. Prevention of COPD exacerbations: a European Respiratory Society/American Thoracic Society guideline. Eur Respir J. 2017;50(3):1602265. doi:10.1183/ 13993003.02265-2016 
49. Peces-Barba G, Barberà JA, Agustí A, et al. [Diagnosis and management of chronic obstructive pulmonary disease: joint guidelines of the Spanish Society of Pulmonology and Thoracic Surgery (SEPAR) and the Latin American Thoracic Society (ALAT)]. Arch Bronconeumol. 2008;44(5):271-281. doi:10.1016/S1579-2129(08)60043-9

50. Tashkin DP, Celli B, Senn S, et al. A 4-year trial of tiotropium in chronic obstructive pulmonary disease. $N$ Engl J Med. 2008;359 (15):1543-1554. doi:10.1056/NEJMoa0805800

51. Andreas S. Effects of LAMA/LABA alone and in combination on cardiac safety. Int $J$ Chron Obstruct Pulmon Dis. 2020;15:1931-1933. doi:10.2147/COPD.S246356

52. Chen Y-F, Cheng Y-C, Chou C-H, Chen C-Y, Yu C-J. Major comorbidities lead to the risk of adverse cardiovascular events in chronic obstructive pulmonary disease patients using inhaled long-acting bronchodilators: a case-control study. BMC Pulm Med. 2019;19 (1):233. doi:10.1186/s12890-019-0999-z

53. European Medicines Agency. Pharmacovigilance Risk Assessment Committee (PRAC): inhaled corticosteroids (ICS) containing medicinal products indicated in the treatment of chronic obstructive pulmonary disease (COPD). Assessment report EMA/330021/2016. 2016.

54. Price D, Yawn B, Brusselle G, Rossi A. Risk-to-benefit ratio of inhaled corticosteroids in patients with COPD. Prim Care Respir J. 2013;22(1):92-100. doi:10.4104/pcrj.2012.00092

55. Martinez CH, Mannino DM, Divo MJ. Defining COPD-related comorbidities, 2004-2014. Chronic Obstruct Pulmon Dis. 2014;1 (1):51-63. doi:10.15326/jcopdf.1.1.2014.0119

56. Hanlon P, Nicholl BI, Jani BD, et al. Examining patterns of multimorbidity, polypharmacy and risk of adverse drug reactions in chronic obstructive pulmonary disease: a cross-sectional UK Biobank study. BMJ Open. 2018;8(1):e018404. doi:10.1136/bmjopen-2017-018404

57. Silva GE, Sherrill DL, Guerra S, Barbee RA. Asthma as a risk factor for COPD in a longitudinal study. Chest. 2004;126(1):59-65. doi:10.1378/chest.126.1.59

58. Baarnes CB, Kjeldgaard P, Nielsen M, Miravitlles M, Ulrik CS. Identifying possible asthma-COPD overlap syndrome in patients with a new diagnosis of COPD in primary care. NPJ Prim Care Respir Med. 2017;27:16084. doi:10.1038/npjpcrm.2016.84

59. Nunez A, Sarasate M, Loeb E, Esquinas C, Miravitlles M, Barrecheguren M. Practical guide to the identification and diagnosis of Asthma-COPD Overlap (ACO). Copd. 2019;16:1-7. doi:10.1080/ 15412555.2019.1575802

60. Cataldo D, Corhay JL, Derom E, et al. A Belgian survey on the diagnosis of asthma-COPD overlap syndrome. Int J Chron Obstruct Pulmon Dis. 2017;12:601-613. doi:10.2147/COPD.S124459

61. Tsiligianni I, Rodriguez MR, Lisspers K, LeeTan T, Infantino A. Call to action: improving primary care for women with COPD. NPJ Prim Care Respir Med. 2017;27(1):11. doi:10.1038/s41533-017-0013-2

62. Langhammer A, Forsmo S, Syversen U. Long-term therapy in COPD: any evidence of adverse effect on bone? Int J Chron Obstruct Pulmon Dis. 2009;4:365-380. doi:10.2147/COPD.S4797

63. Loke YK, Cavallazzi R, Singh S. Risk of fractures with inhaled corticosteroids in COPD: systematic review and meta-analysis of randomised controlled trials and observational studies. Thorax. 2011;66(8):699-708. doi:10.1136/thx.2011.160028

64. Trudzinski F, Vogelmeier C, Buhl R, et al. Inhaled steroids and prevalence of osteoporosis in chronic obstructive pulmonary disease: data from the DACCORD cohort. Eur Respir J. 2020;56(Suppl. 64): 127 .

65. Suissa S, Kezouh A, Ernst P. Inhaled corticosteroids and the risks of diabetes onset and progression. Am J Med. 2010;123(11):1001-1006. doi:10.1016/j.amjmed.2010.06.019

66. Price DB, Russell R, Mares R, et al. Metabolic effects associated with ICS in patients with COPD and comorbid type 2 Diabetes: a historical matched cohort study. PLoS One. 2016;11(9):e0162903. doi:10.1371/journal.pone.0162903
67. Caughey GE, Preiss AK, Vitry AI, Gilbert AL, Roughead EE. Comorbid diabetes and COPD: impact of corticosteroid use on diabetes complications. Diabetes Care. 2013;36(10):3009-3014. doi: $10.2337 / \mathrm{dc} 12-2197$

68. Janson C, Johansson G, Stallberg B, et al. Identifying the associated risks of pneumonia in COPD patients: ARCTIC an observational study. Respir Res. 2018;19(1):172. doi:10.1186/s12931-0180868-y

69. Chalmers JD, Laska IF, Franssen FME, et al. Withdrawal of inhaled corticosteroids in COPD: a European Respiratory Society guideline. Eur Respir J. 2020;55(6):2000351. doi:10.1183/13993003.003512020

70. Pavord ID, Lettis S, Anzuetao A, Barnes N. Blood eosinophil count and pneumonia riks in patients with chronic obstructive pulmonary disease: a patient-level meta-analysis. Lancet Respir Med. 2016;4 (9):731-741. doi:10.1016/S2213-2600(16)30148-5

71. Brassard P, Suissa S, Kezouh A, Ernst P. Inhaled corticosteroids and risk of tuberculosis in patients with respiratory diseases. Am J Respir Crit Care Med. 2011;183(5):675-678. doi:10.1164/rccm.20100710990C

72. Rabe KF, Watz H. Chronic obstructive pulmonary disease. Lancet. 2017;389(10082):1931-1940. doi:10.1016/S01406736(17)31222-9

73. Nielsen AO, Pedersen L, Fischer Sode B, Dahl M. $\beta$-blocker therapy and risk of Chronic Obstructive Pulmonary Disease - a Danish Nationwide Study of 1.3 million individuals. EClinicalMedicine. 2019;7:21-26. doi:10.1016/j.eclinm.2019.01.004

74. Tsiligianni I, Hoines K. Rational use of inhaled medications for the patient with COPD and multiple comorbid conditions: guidance for primary care. International Primary Care Respiratory Group desktop helper no 10; 2019. Available from: https://ipcrg.org/sites/ipcrg/files/ content/attachments/2020-10-28/IPCRG_DTH10_Multimorbidity_ English.pdf.

75. Wang JJ, Rochtchina E, Tan AG, Cumming RG, Leeder SR, Mitchell P. Use of inhaled and oral corticosteroids and the long-term risk of cataract. Ophthalmology. 2009;116(4):652-657. doi:10.1016/j.ophtha.2008.12.001

76. Kesten S, Jara M, Wentworth C, Lanes S. Pooled clinical trial analysis of tiotropium safety. Chest. 2006;130(6):1695-1703. doi:10.1378/chest.130.6.1695

77. Vande Griend JP, Linnebur SA. Inhaled anticholinergic agents and acute urinary retention in men with lower urinary tract symptoms or benign prostatic hyperplasia. Ann Pharmacother. 2012;46 (9):1245-1249. doi:10.1345/aph.1R282

78. Battaglia S, Cardillo I, Lavorini F, Spatafora M, Scichilone N. Safety considerations of inhaled corticosteroids in the elderly. Drugs Aging. 2014;31(11):787-796. doi:10.1007/s40266-014-0213-1

79. Agusti A, Bel E, Thomas M, et al. Treatable traits: toward precision medicine of chronic airway diseases. Eur Respir J. 2016;47 (2):410-419. doi:10.1183/13993003.01359-2015

80. Miravitlles M, Soler-Cataluna JJ, Calle M, Soriano JB. Treatment of COPD by clinical phenotypes: putting old evidence into clinical practice. Eur Respir J. 2013;41(6):1252-1256. doi:10.1183/ 09031936.00118912

81. de Torres JP, Bastarrika G, Wisnivesky JP, et al. Assessing the relationship between lung cancer risk and emphysema detected on low-dose CT of the chest. Chest. 2007;132(6):1932-1938. doi:10.1378/chest.07-1490

82. Barnes PJ. Corticosteroid resistance in patients with asthma and chronic obstructive pulmonary disease. J Allergy Clin Immunol. 2013;131(3):636-645. doi:10.1016/j.jaci.2012.12.1564

83. Patel IS, Seemungal TA, Wilks M, Lloyd-Owen SJ, Donaldson GC, Wedzicha JA. Relationship between bacterial colonisation and the frequency, character, and severity of COPD exacerbations. Thorax. 2002;57(9):759-764. doi:10.1136/thorax.57.9.759 
84. Contoli M, Pauletti A, Rossi MR, et al. Long-term effects of inhaled corticosteroids on sputum bacterial and viral loads in COPD. Eur Respir J. 2017;50(4):1700451. doi:10.1183/13993003.00451-2017

85. Costello RW, Foster JM, Grigg J, et al. The seven stages of man: the role of developmental stage on medication adherence in respiratory diseases. $J$ Allergy Clin Immunol Pract. 2016;4(5):813-820. doi:10.1016/j.jaip.2016.04.002

86. van Schayck O, Wesseling G, Kocks J, Schermer T, Chavannes N. Minder inhalatiecorticosteroïden voor patiënten met COPD. TPO De Praktijk. 2018;13(2):19-21. doi:10.1007/s12503-018-0023-8
87. Cataldo D, Derom E, Liistro G, et al. Overuse of inhaled corticosteroids in COPD: five questions for withdrawal in daily practice. Int J Chron Obstruct Pulmon Dis. 2018;13:2089-2099. doi:10.2147/COPD.S164259

88. Sovani MP, Whale CI, Tattersfield AE. A benefit-risk assessment of inhaled long-acting beta2-agonists in the management of obstructive pulmonary disease. Drug Safety. 2004;27(10):689-715. doi:10.2165/ 00002018-200427100-00001

\section{Publish your work in this journal}

The International Journal of COPD is an international, peer-reviewed journal of therapeutics and pharmacology focusing on concise rapid reporting of clinical studies and reviews in COPD. Special focus is given to the pathophysiological processes underlying the disease, intervention programs, patient focused education, and self management protocols. This journal is indexed on PubMed Central, MedLine and CAS. The manuscript management system is completely online and includes a very quick and fair peer-review system, which is all easy to use. Visit http://www.dovepress.com/testimonials.php to read real quotes from published authors. 